Studia UBB 㚼igitalia, Volume 62 (LXII) 2017, December, Issue 2, 179-186

Published Online: 2017-12-30

DOI:10.24193/subbdigitalia.2017.2.09

\title{
The story of a project: a collective memory 1950-2000
}

\author{
Andrada Cațavei \\ Collage City. Art. Architecture. NPO, Bucharest, Romania
}

\begin{abstract}
Conceived and started in 2007 as a result of a private initiative, the collective memory 1950-2000 transdisciplinary project is one whose story (creation, evolution, valorization) is of great interest in the history of digitalization in Romania. As one of the pioneering project of digitalization in the country, it focuses on the creation of an online image archive (www.memoriecolectiva.org) and of its contemporary cultural use. Dedicated to Romanian images especially but not only from the 1950-2000 period, is unique in the field both on the Romanian and international level by how it was conceived, theme, concept, complexity and display.

Part of its uniqueness and values is due to the fact that besides collecting, preserving, archiving, digitalizing or presenting the images online it has an oral history component by presenting all the images together with records (voice, video, text) of their stories or/and the stories of their collectors or photographers. Thus an interesting and important asset of the project come into be discuss: the fact that the archive is an emotional one even if is created to be impartial, to have a scientific approach, to promote and encourage researchers and artists to work with it patrimony and an important part of the project it's dedicated to research, study and to the cultural exploiting of the online archive.
\end{abstract}

Keywords: Anthropology; art history; collective memory; image; memories; national; online archive; oral history; patrimony; photography; research; Romania; story; value; vernacular 
Collective memory 1950-2000 is an online archive started in the Bucharest of 2007 emerged from an art history and anthropology type of approach as one of the pioneering projects of digitalization in Romania.

The project idea come out as a result of an enthusiastic meeting I had as an art historian in 2007 with loana Daia, friend and anthropologist, member of the contemporary anthropology research team generated and developed around the special figure of Irina Nicolau. We were both formed by that special 90's anthropology research emulation that flourished in the prolific ambiance of what was The Romanian Peasant Museum from Bucharest under the rule of the artist Horia Bernea.

The purpose of the meeting was to decide whether to write an article about the photo collection inherited by the photographer Florin Bobu, after the death of his childhood photography mentor, a casual and amateur village photographer that helped the villagers record their private or administrative events (identity card photos, weddings, funerals etc.). During this meeting, we have realized the fantastic potential (anthropological, sociological, technical, historical, artistic, emotional etc.) of the vernacular images created by ordinary people or amateur photographers and the importance of saving them from being abandoned or destroyed. Following the urge to do something significant to protect and put into value such a legacy we end up by being drive by the idea of collecting, preserving and making available images of yesteryears that captured lives and stories from the past, to the present and into the future. Thus, the meeting didn't end up with an article but with an idea to create a project and an archive: the collective memory 1950-2000!

A team was soon created which developed in time to become a management, scientific \& research board. Later the team was enlarged with specialists and volunteers collaborating to conduct and implement research, digitalization, events, etc. but meanwhile loana Daia's idea to associate the images that we wanted to collect with their stories was developed and step by step the concept of this special archive emerged into becoming a unique transdisciplinary project on a national scale.

The collective memory $1950-2000$ project is about the creation of a new archive concept, definitely more than just grouping images and their stories as an emotional/ nostalgic online album of Romania in between 1950-2000. The purpose of the project is to create and to develop: a professional online, accessible and free archive; to recuperate, collect, preserve, analyse and synthesis in a professional way and to display in an accessible user friendly way a considerable number of images together with their stories in order to make use of the reach mnemonic load of the archive, to provide an important resource for future national or international cultural, anthropology, art, history, oral history, sociology, architecture, interior design etc. studies! 
The creation of a private archive conceived to be online, open, with free access to the public was something unheard of in the bureaucratic Romania of the first decade of the 2000's. All the archives were State institutions with limited public access, slow and bureaucratic consultation procedures, not digitalized and with websites that were presenting the institution itself, not the patrimony they posed. Thus by analyzing and scanning all the collected images, by presenting them online and by developing a special adapted data base system behind the website created by our collaborators especially for us, the collective memory $1950-2000$ project was pioneering the image digitalization in Romania and creating an accessible archive available quick worldwide. The access to the images is free but all the images are protected by national and international specific lows because the image use politic was special created both to protect the images, collectors, photographs but also to facilitate their cultural valorization!

The choice made in 2007 to document 50 years of recent Romanian troubled history was again for that time a pioneering and very courageous act because there were almost no national, academic, public or private interests for that specific period or for vernacular images. Strong emotions on a national and personal level were associated with almost everything that happened before 1989, leading to an attempt to re-order or get rid of the past and to embrace the new fashions on every aspect of life. Only in the last few years has it become fashionable to be interested from an academic point of view in the period before 1989 and the emotional approach regarding that historic period becomes a bit more balanced. This was the context in which the collective memory 1950-2000 project aimed to document with a scientific and impartial approach, an unstudied period of time in order to create a study base to understand a period with important, dramatic and fast transformation in every aspect of public and personal life (political, economic, social, mentality, technical etc.). Thus the archive contains images from Romania, especially but not only, from 1950 to 2000, mainly photography but also postcards, cards, wedding invitations, labels etc. The images are from different regions, cities or villages; shot in public or private occasions; captured by professional or amateur photographers; staged or vernacular; gathered from private or public collections or from family albums etc.

Since 2008, the archive is collecting images of every format, size, subject, type or support (photographic paper, film, negatives, glass etc.) by organizing research and collecting campaigns all over the country or by receiving image donations. Due to the fact that the creation and development of the collective memory 1950-2000 archive is an ongoing process the archive is flexible and permanently open to donations and any type of collaborations. 
The material is analyzed, catalogued, archived and digitalized on scientific criteria then, based on the previous signed accords with their owners/collectors/donators, is uploaded online together with the personal stories and information (text, audio or video) about the author, collector/s or the collection they belong to. Developing it unique concept, the online image archive is not focusing only on presenting the technical data of the images following the scientific archivist procedures, but on putting in the spotlight the fact that all these images whether they be snapshots of everyday life or staged photographs, are actually personal stories that could recreate the history they carry both for the today's researchers and for the ordinary observer.

In this way as many image collections are added to the archive, as many stories will be shared and, due to the fact that the archive contained collections of images and stories of public figures from different domains (sport, culture, medicine, engineering, inventions, education, architecture, arts, music, theatre, film, business, etc.) together with the images and stories of ordinary people, the archive become an incredible information source capable of recreating and expressing all the changes in Romanian society in the last few decades.

In order to make all this rich and incredible material known and available to the general public and the specialists, the project was designed from conception to encourage all types of scientific or artistic research, collaborations and cultural exploiting of the digital/material image collections it has. To set the tone, several artistic shows and art performances were made as part of cultural events with large numbers of participants. Proposals for international and national conferences, seminars, publications, call for artistic projects based on the archive images etc. are to follow. But, regarding the promotion of the archive, the project brought another huge novelty in the Romanian ambiance of the first decade of the 2000's: the collective memory 1950-2000 archive was conceived as a brand!

The fact that a cultural transdisciplinary project with this topic, this scale and with such complexity on all its levels able to combine a high level of professionalism with accessibility emerge as a result of a private initiative, was unprecedented in Romania! It creation and realization was possible with the trust and help from families, friends, specialists, collaborators, official partners and the essential financial support of the ERSTE Foundation!

However, being pioneers means facing all sort of problems and then finding or creating solutions to solve them; making many mistakes and, if possible, learning from them! We have experienced challenges from this point of view on all the fields we have dealt with: technical, logistics, efficiency, mentality, etc. but the main ones were of technical and emotional nature. 
First one because the building of an online archive, the digitalization process, it technics, systems, storage and all the procedures associated with were novelties at the time we have started. With only a few and not remarkable Romanian experiences on the online digitalization field until 2007 we've studied and learned from the international examples, procedures and systems trends on online archives, digital archiving process, data bases, news agencies, image banks, stock photography, online commerce, photo sites etc. Followed those studies and being inspired especially by models like Getty, Magnum, Alinari we have conceived our own digital archive system and website. The process was slow and with lots of experiments and tests but from 2009, we were able to have the first functional online version of the archive and the website, created and tailored for our interests and needs only. The need for an upgrade version followed soon, in 2012 and it was due to the fast changes on technology and to the improvements that we have brought to the archive operational system. Being an active archive, interested to keep a contemporary fresh approach and to make use of all the useful updates (on scientific and technological aspects of digitalization, archive procedures or cultural valorization), an updated version of it is now discussed and in tests.

The core of the archive is the search system and due to the fact that's always to be improved, we have faced many problems on this matter. A curious and interesting aspect of it is the fact that emotional particularities of the archive made out of the search system criteria a difficult task for all the tree versions of the online archive, both from scientific and technic aspects!

Actually, except the technical matters that challenged us, the main problem we face is: emotions!

First, any archive is by default emotional even if resulted from the austerity of the scientific approach of the specific archiving methods and rules. By being different, collective memory 1950-2000 archive has the emotional approach of being an archive designed to accompany images with their stories and the stories of their photographers and collectors. More, this archive is unique in the field by being dedicated to recent history, a period of time rich in transformation (political, economic, cultural, mentality etc.) and this is always very controversial and accordingly, extremely sensitive regarding emotions!

As this was not enough, by being an ongoing project and by having open and direct contact with the users or the contributors to the creation of the archive and with the public from the events that we have organized, the archive is constantly exposed to different emotional reactions.

The most common of them is a mentality problem: the negative attitude expressing mistrust regarding the use of the archive for cultural and impartial purposes and it importance for nowadays and the future. This mistrust is one of the effects generated 
in a subliminal way by the last decades of dramatic and traumatic transformations (political, economic, social, cultural etc.) that lead to a general lack of values, respect, selfesteem, indifference and eventually, to the alteration of the individuals.

In contrast, other type of reaction we face is the positive one, that understand, embrace and sustain our concept but has often the tendency to reach a point of developing a glorification of the past. This is characteristic for the young generation born in the 1990's that are curious about the past but due to the globalisation new phenomena of a "shallow" and "political correct" type of society, they refer to the past with a consumer interest, searching in it for "cool" aspects that can "decorate" their life.

But this are just the two dominant types of emotional reactions that we face directly because in the Romanian society of the last few decade emotional reactions are of many type and in constant change, fluctuating between complete indifference and strong emotions (excessive positive: propaganda, emphasis, empty patriotism or excessive negative: mistrust, destructive, resignation).

In such a context generated by fast mentality and society changes, we considered mandatory for the collective memory 1950-2000 archive to have an impartial role. That is why we did not want to develop any nostalgic, melancholic, propagandistic, emphatic, populist, patriotic etc. "tone" of the archive but neither a too academic one with a strong accent on data/archivist criteria. We were interested to develop an impartial and active archive with a neutral display by promoting acceptance of the all the realities/facts of the past, a scientific type of approach, academic without being rigid or to descriptive and an agenda of different type of cultural events. That's why the archive itself and everything connected with it (events, shows, visuals etc.) is well analyzed by the scientific, research and development board in order to be balanced from an emotional point of view and to be able to express the impartiality concept of the project!

The politic of the archive is not to judge but to collect in a professional way images and to record their stories/memories in order to be able to be analysed in scientific ways, leaving the story or image perception to depend on the viewers/receivers themselves. But even if we put a lot of work to build an impartial approach by running such a specific archive we are kind of trapped in between the emotions from within the archive itself and the external ones (society, viewers, etc.). This is the reason why we decided to explore certain aspect of this phenomenon and to make use of emotions and the emotional potential of the archive in order to promote a kind of statement regarding the archive politic.

The images and stories of the images, collectors or photographers we present in the archive are nothing else than fragments of life and life experiences/lessons. In this context every image, every story of the images and the story of every path and every individual become important. Thus, every image and story presented in the archive 
is becoming part of a process of discovering who we are as individuals. But by gathering together the multitude of the images and stories that we've collect, the project of creating an impartial digital archive become in a natural way, more than just an impartial images \& stories collection of all the different collections that we preserve! Even if we remain impartial and we do not interfere on the other side of a professional approach, we are actually creating an emotional archive about people, their memories, experiences and life! Thus the collective memory 1950-2000 archive becomes a kind of image album with stories about ALL OF US and extrapolating, an IMAGE OF ROMANIA itself!

This archive is a personal experience! It images and stories express all the change of the society and for the fact that is mirroring the realities of a period, group, etc. collective memory 1950-2000 archive is an image of Romania and it transformations! Is reflecting how we are! Is not just data! Is who we are! It consists of many image and story collections together and because they all are nothing else than memories, this archive it become a memory archive. By being a collection of OUR memories it shows the deep humanity of each of us and the fact that personal mistakes, dreams, failures, happiness, etc. become/are/can be collective or even national mistakes dreams, failures, happiness, etc. Thus this archive it contains our collective memory!

In this way, the archive is becoming so rich in emotions in all its impartiality, that any type of viewer can find in it a place for a personal introspection research. A direct contact with the archive is enabling for the viewer the exploration of WHO YOU ARE as an individual and who you are as a part of a family, group, country, a period in time, a generation etc. With this introspection process that lead from personal to collective/national, the archive project is developing in a spontaneous way and in the exact same time with it's creation, a WAY OF THINKING about the past, a type of ATTITUDE to the past, a SOLUTION to sort out the "problems that we have with the past": to use the material of the archive to discover with an honest approach who you are, to accept and to assume it in order to be able move on and to develop!

We have expressed this statement in public by exploiting the emotional and material potential of the archive within the three shows organised in Bucharest in 2009 at the Romanian Peasant Museum and in 2012 in Sutzu Palace. We were interested to create direct interferences of viewers/spectators with images from the archive collections trough performances that allowed communication, connection, mirroring, confronting personal experiences with the one of others. Focusing on the interactions in between images and the fragility, ephemerality, fluidity of emotions/memory/life we've explored and stimulated a process of introspection (identity; individual experience-memory as a "belonging feeling"; personal-collective/national; discover-accept-assume-get over it and go on) by using new media technology, indoor projections, outdoor big scale projections, vapour screen projections or prints on mirror surfaces. 
This is an example of how we've make use of some of the emotional aspects of the archive and how we've presented a statement but due to the fact that the archive is formed by a large amount of image \& story collections from all Romania, it potential is extremely rich, valuable and interesting for personal/individual or collective exploration (including a post trauma therapeutic process on individual or collective levels regarding the period before 1989) and for many professional research/study fields! With such a context, the politic of the archive is to promote and to put in value all it patrimony and in as many ways can be possible. The archive is open to collaborations for projects, studies, researches on different domains (art history, history, anthropology, sociology, psychology, architecture, etc.). We encourage scientific researches, biographies/monographic studies on the photographers/collectors or on people (famous or not yet) presented in the images of the archive and any type of photographic studies: on what the images of the archive depict (landscapes, architecture, houses, portraits, objects, people and ways of being, fashions, etc.) or on the evolution of photography (technic, materials, way of posing, attitudes of the subjects in front of the camera, styles and fashion of doing photos, etc.), etc. We also consider ways of working with any type of creative: artist or new-media artists, photographers, designers, architects, scenographers, movie/theatre directors, fashion designers, etc. Thus by collecting, preserving, studying and promoting the fantastic potential of the unique patrimony of collective memory 1950-2000 archive, researchers and viewers/spectator together we can build and explore our collective memory. 